\title{
Prevention of secondary household transmission during Shiga toxin-producing Escherichia coli outbreaks
}

\author{
K. TOKUDA ${ }^{1 *}, Y$ Y. YAHATA ${ }^{2}$ AND T. SUNAGAWA ${ }^{2}$ \\ ${ }^{1}$ Department of Infection Prevention and Control, Division of Medical and Environmental Safety, Kagoshima \\ University Medical and Dental Hospital, Kagoshima, Japan \\ ${ }^{2}$ National Institute of Infectious Diseases, Shinjuku-ku, Tokyo, Japan
}

Received 20 August 2015; Final revision 9 May 2016; Accepted 23 May 2016;

first published online 13 June 2016

\section{SUMMARY}

Prevention of secondary household transmission of Shiga toxin-producing Escherichia coli (STEC) is important in outbreak settings. We examined factors contributing to secondary household transmission during STEC outbreaks in daycare centres in Japan. Suspected STEC outbreaks in daycare centres were identified by the National Epidemiological Surveillance of Infectious Diseases. Questionnaires were sent to local health centres that responded to outbreaks. Secondary household transmission rates were calculated, and factors affecting secondary household transmission rate were analysed by multilevel analysis. The secondary household transmission rates in 16 outbreaks ranged from $0 \%$ to $34 \cdot 4 \%$ (median $4 \cdot 4 \%$ ). The highest rate $(23.0 \%)$ was observed in siblings aged 6-9 years, and the infection rate was significantly higher for mothers than for fathers and grandparents $(P<0 \cdot 05)$. Using multilevel analysis, the following variables were selected in the best model: information provided face-to-face ( $v s$. letter or telephone) to families of children in daycare centres (at initial response), STEC type and lag time (days) between onset and providing information. Early response and hygiene education by visiting local health centre staff may be effective measures to prevent secondary household transmission in STEC outbreaks. Hygiene education should be emphasized for children aged 6-9 years, as well as for younger children.

Key words: Incidence, outbreaks, Shiga-like toxin-producing E. coli, transmission.

\section{INTRODUCTION}

In Japan, all cases of Shiga toxin-producing Escherichia coli (STEC) infection are notifiable according to the Law Concerning the Prevention of Infectious Diseases and Medical Care for Patients of Infections (the Infectious Diseases Control Law). Since 1999, 3000-4000 cases, including carriers, of

\footnotetext{
* Author for correspondence: Dr K. Tokuda, Department of Infection Prevention and Control, Division of Medical and Environmental Safety, Kagoshima University Medical and Dental Hospital, Sakuragaoka 8-35-1, Kagoshima 890-8520, Japan. (Email: tokuda@m3.kufm.kagoshima-u.ac.jp)
}

STEC infection have been reported annually. In 2014, 4153 cases (2839 with gastroenteritis and 1314 asymptomatic STEC carriers) were reported [1].

The number of reported cases has gradually increased since 2002. In addition, more than 20 foodpoisoning STEC outbreaks were reported for 3 consecutive years from 2005 to 2007 for the first time. STEC outbreaks occur every year in facilities such as institutions for the elderly and restaurants. Furthermore, reports of STEC outbreaks in infant daycare centres (DCCs), such as nurseries and crèches, are common [1, 2]. Because STEC infection can be established by trace levels of bacteria 
$\left(10^{2}\right.$ cells), secondary transmission from person-toperson can easily occur [3, 4]. In Japan, DCCs often provide study meetings for guardians about appropriate responses to infection, including preventive measures to combat household transmission, in collaboration with local health centres.

Secondary household transmission (SecHT) of STEC infection has also been reported both within and outside of Japan [2, 5-7]. According to the Infectious Diseases Control Law, if cases of STEC infection (including asymptomatic carriers) are detected at medical institutions in Japan, they must be reported promptly to local health centres. Immediately following notification, the local health centre in question is required to investigate the source and route of infection and examine all people, including family members, who have been in contact with the patient to determine whether they are carriers, thereby preventing the spread of infection. In the event of an outbreak, the local health centre should take appropriate measures and conduct the necessary surveys in cooperation with the facility in question.

Several reports have described the importance of preventing secondary transmission and the necessity of limiting attendance at work, school, and childcare facilities to prevent the spread of infection [8-10]. However, few studies have investigated which factors contribute to secondary transmission and to the spread of infection in families of infected children.

The present study was conducted to accurately assess the actual status of SecHT of STEC by children infected at DCCs, and to investigate which factors contribute to SecHT, such as measures implemented by local health centres and epidemiological characteristics of the outbreaks. These findings will assist in developing appropriate intervention practices for local health centres and other related public health services.

\section{MATERIALS AND METHODS}

\section{Study period and subjects}

A retrospective cohort study was conducted to examine the risk of secondary transmission. All STEC outbreaks (including all serogroups) involving $\geqslant 10$ children at a DCC in 2006 were investigated.

Because there is no reporting standard for STEC outbreaks, with the exception of foodborne outbreaks, we performed a retrospective search to find STEC outbreaks using a national surveillance system in which
STEC infection is classified as a mandatory reportable disease. We determined that real outbreaks might be found effectively if we searched clusters of $\geqslant 10$ cases that complied with the standards for outbreaks of nosocomial infections in medical facilities.

\section{Identification of outbreaks}

To detect suspected outbreaks that occurred at DCCs in 2006, regions where $\geqslant 10$ STEC-infected children aged $0-6$ years were reported during the target period were identified from the National Epidemiological Surveillance of Infectious Diseases (NESID), conducted by the Ministry of Health, Labour, and Welfare according to the Infectious Diseases Control Law. If $\geqslant 10$ STEC-infected children attended the same DCC, it was defined as an outbreak.

\section{Questionnaire survey}

Questionnaires were sent to the local health centres supervising regions with suspected outbreaks to collect the following information: (1) outbreaks involving $\geqslant 10$ children in DCCs; (2) information regarding STEC-positive children [age, symptomatic or asymptomatic, NESID enrolment no. (ID)]; (3) information about the families of STEC-positive children (family structure, presence or absence of infected persons, symptoms); (4) the date families of infected children were provided with information on coping with infection by the local health centres; and (5) how the information was provided (e.g. letter, telephone, explanatory meeting, or home visit) by the local health centres. In addition to questions about measures conducted by local health centres, questions about measures taken by DCCs included: (1) the date at which information was provided to families of DCC children; and (2) how information was provided (e.g. letter, telephone, explanatory meeting, and/or home visit).

Subsequently, we collected information from NESID for the following items: (1) date of diagnosis of the first patient (the initial case) at a medical institution for each outbreak; (2) date when the medical institution notified the local health centre; and (3) information about STEC-positive cases [pathogen characteristics (O serogroup and Shiga toxin (Stx) type], symptomatic or asymptomatic).

Information about STEC-positive children and their family members was obtained as anonymized 
data, i.e. no names or identifying information were collected in our study.

\section{Assessment of the status of SecHT}

We designed our study to reveal the actual status of SecHT caused by children as infectious sources. In the present study, family members who returned a STEC-positive faecal sample with the same $O$ serogroup and Stx type as the outbreak pathogen were classified as being infected by SecHT. The onset of illness had to have occurred at least 2 days and not more than 14 days after the onset of the initial case. Patients in whom a positive STEC test and symptoms of gastroenteritis were noted simultaneously were classified as having STEC gastroenteritis.

Based on the information obtained from the questionnaire survey and from NESID, the SecHT rate was calculated for families with only one child who was suspected of having STEC. Families with $\geqslant 2$ children attending the DCC were excluded from analysis even if faecal examination detected STEC in only one child; thus, SecHT from a single infectious source only was analysed in this study. The SecHT rate was calculated as the total number of infected cases per total number of family members in each outbreak, excluding children attending the DCC in question.

The $\chi^{2}$ test (or Fisher's exact probability test) and the Cochrane-Armitage trend test were used to examine differences and trends, respectively. These analyses were conducted using SPSS v. 23.0 (IBM Corp., USA) or JMP v. 11 (SAS Institute, USA). $P<0.05$ was considered statistically significant.

\section{Analysis of factors contributing to SecHT}

To identify factors contributing to the SecHT rate, explanatory variables relevant to intervention by local health centres and the epidemiological characteristics of the outbreaks were selected, and multilevel analysis was performed. The variables used and their definitions were as follows: (1) lag time (days) between onset and providing information was defined as the time interval (days) between diagnosis at a medical institution and provision of guidance on coping with infection to families; (2) age (years) of STEC-positive DCC children was defined as the age of the STEC-positive children affected in DCCs in each outbreak; (3) presence (vs. absence) of symptoms in STEC-positive DCC children was defined as the presence or absence of STEC-positive children with symptoms in each family during an outbreak; (4) STEC type was a dummy variable representing the O serogroup and Stx type of STEC in each outbreak; (5) information provided face-to-face ( $v s$. letter or telephone) to families with STEC-positive children (at initial response) was a dummy variable representing the method by which the DCCs or local health centres provided guidance on coping with infection to families with STEC-positive children at initial response [letter or telephone vs. face-to-face contact (explanatory meeting or home visit)]; (6) information provided face-to-face ( $v s$. letter or telephone) to families with STEC-negative children (at initial response) was a dummy variable representing the method by which the DCCs or the local health centres provided guidance on coping with infection to families with STEC-negative children at initial response [letter or telephone vs. face-to-face contact (explanatory meeting or home visit)]; (7) information provided face-to-face ( $v s$. letter or telephone) to families with STEC-negative children (after initial response) was a dummy variable representing the method by which the DCCs or the local health centres provided guidance on coping with infection to families with STEC-negative children after initial response [letter or telephone $v s$. face-to-face contact (explanatory meeting or home visit)]; and (8) ordinary measures for families was a dummy variable representing the presence or absence of education for families about infection prevention measures prior to the STEC outbreaks.

SPSS v. 23.0 (IBM Corp.) was used for multilevel analysis. These eight variables were tested in a stepwise fashion based on the result of single regression analysis conducted as the preliminary analysis (data not shown). Differences of $P<0.05$ were considered significant.

\section{RESULTS}

\section{Status of SecHT}

Suspected STEC outbreaks at DCCs were identified from the NESID data for regions under the jurisdiction of 18 local health centres in 17 prefectures, and questionnaires were sent to these 18 local health centres. The collection rate was $100 \%$. It was confirmed that 16 outbreaks occurred in the territories of 15 local health centres in 14 prefectures (Table 1). The local health centres in question conducted active case-finding including bacteria tests for DCC children and family members of STEC-positive DCC children. 
Table 1. Secondary household transmission rate and pathogens in each outbreak

\begin{tabular}{lclccl}
\hline \hline $\begin{array}{l}\text { Daycare } \\
\text { centre }\end{array}$ & $\begin{array}{l}\text { No. of STEC-positive } \\
\text { daycare centre children* }\end{array}$ & $\begin{array}{l}\text { No. of family } \\
\text { members }\end{array}$ & $\begin{array}{l}\text { No. of } \\
\text { infected cases }\end{array}$ & $\begin{array}{l}\text { Secondary household } \\
\text { transmission rate }(\%)\end{array}$ & $\begin{array}{l}\text { STEC O } \\
\text { serogroup/Stx type }\end{array}$ \\
\hline A & 17 & 43 & 0 & $0 \cdot 0$ & O26/Stx1 \\
B & 8 & 21 & 6 & $28 \cdot 6$ & O157/Stx1 and Stx2 \\
C & 8 & 35 & 0 & $0 \cdot 0$ & O26/Stx1 \\
D & 18 & 72 & 2 & $2 \cdot 8$ & O26/Stx1 \\
E & 23 & 94 & 6 & $6 \cdot 4$ & O26/Stx1 \\
F & 30 & 96 & 2 & $2 \cdot 1$ & O157/Stx1 and Stx2 \\
G & 17 & 47 & 12 & $25 \cdot 5$ & O26/Stx1 \\
H & 7 & 17 & 1 & $5 \cdot 9$ & O157/Stx1 and Stx2 \\
I & 5 & 36 & 1 & $2 \cdot 8$ & O26/Stx1 \\
J & 10 & 32 & 11 & $34 \cdot 4$ & O157/Stx1 and Stx2 \\
K & 6 & 20 & 0 & $0 \cdot 0$ & O157/Stx1 and Stx2 \\
L & 13 & 26 & 2 & $7 \cdot 7$ & O26/Stx1 \\
M & 12 & 48 & 0 & $0 \cdot 0$ & O26/Stx1 \\
N & 20 & 71 & 18 & $25 \cdot 4$ & O26/Stx1 \\
O & 8 & 36 & 8 & $22 \cdot 2$ & O26/Stx1 \\
P & 20 & 57 & 0 & $0 \cdot 0$ & \\
Total & 222 & 751 & 69 & $9 \cdot 2$ & \\
\hline \hline
\end{tabular}

Stx, Shiga toxin.

* No. of STEC-positive daycare centre children whose families met the requirements for calculating the secondary household transmission rate.

Because the bacteria tests were conducted for contacts regardless of their symptoms, asymptomatically infected people were also reported.

The local health centres investigated 1564 subjects from 327 families, including STEC-positive DCC children and their family members. Of family members, 444 subjects were children attending the DCCs in question. A total of 1120 family members were investigated, and 751 met the requirements for calculating the SecHT rate. These included 339 males and 412 females, and the SecHT rate and the incidence of gastroenteritis showed no gender differences.

The SecHT rate during each of the outbreaks ranged from $0 \%$ to $34 \cdot 4 \%$ (median $4 \cdot 4 \%$ ). In 16 STEC outbreaks occurring at DCCs during 2006, two types of STEC strains were detected: an $\mathrm{O} 26$ Stx1-producing STEC strain was identified in 11 outbreaks, while O157 Stx1- and Stx2-producing STEC strains were present in five outbreaks (Table 1).

Of the 222 STEC-positive DCC children, the agespecific incidence of gastroenteritis of children aged from 1 to 6 years was $40 \cdot 1 \%, 42 \cdot 1 \%, 48 \cdot 0 \%, 42 \cdot 5 \%$, $29 \cdot 2 \%$ and $0 \%$, respectively. A STEC-positive DCC child aged 0 years (aged $<1$ year) was not detected in any of the 16 outbreaks.

Age was reported for 711 of the 751 family members. The highest SecHT rate $(23.0 \%)$ was identified in children aged 6-9 years, followed by $15 \cdot 4 \%$ in children aged $0-5$ years (Table 2). Both the SecHT rate and the incidence of gastroenteritis significantly increased in the younger age groups $(P<0 \cdot 001)$. The highest rate of SecHT for family members was $21.3 \%$ in brothers, followed by $18.3 \%$ in sisters, and $10.0 \%$ in mothers (Table 2). The SecHT rate in brothers was significantly higher than that in mothers $(P<0 \cdot 05)$. Additionally, the SecHT rate in mothers was significantly higher than that in fathers, grandfathers, and grandmothers $(P<0.05, P<0.05$, and $P<0 \cdot 01$, respectively).

When the SecHT rate was calculated relative to the age of the STEC-positive DCC children who transmitted the organism to the families, the SecHT rate in the families with children aged 1-4 years significantly increased with a decrease in age $(P<0 \cdot 001)$, but significantly increased with an increase of age in families with children aged 4-6 years $(P<0 \cdot 001)$ (Table 3$)$.

For STEC-positive DCC children, the SecHT rate was $8.2 \%$ for those with symptoms of gastroenteritis and $9.9 \%$ in the asymptomatic group, which was not significantly different. In families of STEC-positive DCC children, the incidence of gastroenteritis was higher in family members with symptomatic DCC children than in those with asymptomatic DCC children $(2.0 \%$ and $1.3 \%$, respectively), which was not significantly different. The SecHT rate was $8.7 \%$ in the group infected with the O26 Stx1-producing STEC strain, and $10 \cdot 8 \%$ in the group infected by the 
Table 2. Secondary household transmission rate and incidence of gastroenteritis in each age group and family members $(n=711)$

\begin{tabular}{|c|c|c|c|c|c|}
\hline & $\begin{array}{l}\text { No. of family } \\
\text { members }\end{array}$ & $\begin{array}{l}\text { No. of } \\
\text { infected cases }\end{array}$ & $\begin{array}{l}\text { Secondary household } \\
\text { transmission rate* }(\%)\end{array}$ & $\begin{array}{l}\text { No. of cases with } \\
\text { gastroenteritis }\end{array}$ & $\begin{array}{l}\text { Incidence of } \\
\text { gastroenteritis* } \\
(\%)\end{array}$ \\
\hline \multicolumn{6}{|l|}{ Age group (years) } \\
\hline $0-5$ & 39 & 6 & $15 \cdot 4$ & 3 & $7 \cdot 7$ \\
\hline $6-9$ & 74 & 17 & $23 \cdot 0$ & 4 & $5 \cdot 4$ \\
\hline $10-19$ & 37 & 4 & $10 \cdot 8$ & 2 & $5 \cdot 4$ \\
\hline $20-29$ & 79 & 8 & $10 \cdot 1$ & 2 & $2 \cdot 5$ \\
\hline $30-39$ & 270 & 23 & $8 \cdot 5$ & 0 & $0 \cdot 0$ \\
\hline $40-49$ & 63 & 7 & $11 \cdot 1$ & 1 & $1 \cdot 6$ \\
\hline $50-59$ & 58 & 1 & $1 \cdot 7$ & 0 & $0 \cdot 0$ \\
\hline$\geqslant 60$ & 91 & 3 & $3 \cdot 3$ & 0 & $0 \cdot 0$ \\
\hline \multicolumn{6}{|l|}{ Family members } \\
\hline Father & 178 & 8 & $4 \cdot 5$ & 1 & $0 \cdot 6$ \\
\hline Mother & 201 & 20 & $10 \cdot 0$ & 2 & $1 \cdot 0$ \\
\hline Brother & 61 & 13 & $21 \cdot 3$ & 4 & $6 \cdot 6$ \\
\hline Sister & 71 & 13 & $18 \cdot 3$ & 5 & $7 \cdot 0$ \\
\hline Grandfather & 59 & 1 & $1 \cdot 7$ & 0 & $0 \cdot 0$ \\
\hline Grandmother & 90 & 1 & $1 \cdot 1$ & 0 & $0 \cdot 0$ \\
\hline Other family member & 51 & 13 & $14 \cdot 8$ & 0 & $0 \cdot 0$ \\
\hline Total & 711 & 69 & $9 \cdot 7$ & 12 & $1 \cdot 7$ \\
\hline
\end{tabular}

* Trend in age groups from $0-5$ until $\geqslant 60$ years $(P<0 \cdot 001)$.

Table 3. Secondary household transmission rate and incidence of gastroenteritis stratified by the age of STEC-positive daycare centre children $(n=751)$

\begin{tabular}{|c|c|c|c|c|c|c|}
\hline $\begin{array}{l}\text { Age of } \\
\text { STEC-positive } \\
\text { daycare centre } \\
\text { children (years) }\end{array}$ & $\begin{array}{l}\text { No. of } \\
\text { STEC-positive } \\
\text { daycare centre } \\
\text { children }\end{array}$ & $\begin{array}{l}\text { No. of } \\
\text { family } \\
\text { members }\end{array}$ & $\begin{array}{l}\text { No. of } \\
\text { infected } \\
\text { cases }\end{array}$ & $\begin{array}{l}\text { Secondary } \\
\text { household } \\
\text { transmission } \\
\text { rate* }(\%)\end{array}$ & $\begin{array}{l}\text { No. of cases with } \\
\text { gastroenteritis }\end{array}$ & $\begin{array}{l}\text { Incidence of } \\
\text { gastroenteritis }(\%)\end{array}$ \\
\hline 0 & 0 & 0 & 0 & - & 0 & - \\
\hline 1 & 42 & 128 & 18 & $14 \cdot 1$ & 2 & $1 \cdot 6$ \\
\hline 2 & 56 & 166 & 24 & $14 \cdot 5$ & 0 & $0 \cdot 0$ \\
\hline 3 & 48 & 163 & 11 & $6 \cdot 7$ & 5 & $3 \cdot 1$ \\
\hline 4 & 41 & 170 & 2 & $1 \cdot 2$ & 0 & $0 \cdot 0$ \\
\hline 5 & 23 & 85 & 4 & $4 \cdot 7$ & 1 & $1 \cdot 2$ \\
\hline 6 & 12 & 39 & 10 & $25 \cdot 6$ & 4 & $10 \cdot 3$ \\
\hline Total & 222 & 751 & 69 & $9 \cdot 2$ & 12 & $1 \cdot 6$ \\
\hline
\end{tabular}

* Trend in 1-4 years age group $(P<0 \cdot 001)$; trend in $4-6$ years age group $(P<0 \cdot 001)$.

O157 Stx1- and Stx2-producing STEC strains, which was not significantly different. The incidence of gastroenteritis was $1.6 \%$ in both groups.

\section{Analysis of factors contributing to SecHT}

Table 4 summarizes the descriptive statistics for each variable employed in the regression analysis. For multilevel analysis, models were prepared according to Akaike's Information Criterion and Schwarz's Bayesian Information Criterion. As a result, four variables were selected (Table 5). Information provided face-to-face ( $v s$. letter or telephone) to families during the early response was the most closely related variable. The SecHT rate was lower when information was provided face-to-face than by letter or telephone, 
Table 4. Response variable and explanatory variables

\begin{tabular}{|c|c|c|c|}
\hline Variable & $N$ & $\%$ & \\
\hline \multicolumn{4}{|l|}{ Response variable } \\
\hline \multicolumn{4}{|l|}{ Secondary household transmission } \\
\hline Yes & 69 & $9 \cdot 2$ & \\
\hline No & 682 & $90 \cdot 8$ & \\
\hline \multicolumn{4}{|l|}{ Explanatory variable (qualitative) } \\
\hline \multicolumn{4}{|l|}{ Symptoms in STEC-positive daycare centre children } \\
\hline Presence & 305 & $40 \cdot 6$ & \\
\hline Absence & 446 & $59 \cdot 4$ & \\
\hline \multicolumn{4}{|l|}{ STEC type } \\
\hline O26 Stx1-producing STEC & 565 & $75 \cdot 2$ & \\
\hline O157 Stx1 and Stx2-producing STEC & 186 & $24 \cdot 8$ & \\
\hline \multicolumn{4}{|c|}{ Information provided face-to-face ( $v s$. letter or telephone) to families with } \\
\hline \multicolumn{4}{|c|}{ STEC-positive children (at initial response) } \\
\hline Letter, telephone & 68 & $9 \cdot 1$ & \\
\hline Face-to-face contact & 683 & $90 \cdot 9$ & \\
\hline \multicolumn{4}{|c|}{ Information provided face-to-face ( $v s$. letter or telephone) to families with } \\
\hline \multicolumn{4}{|l|}{ STEC-negative children (at initial response) } \\
\hline Letter, telephone & 551 & $73 \cdot 4$ & \\
\hline Face-to-face contact & 200 & $26 \cdot 6$ & \\
\hline \multicolumn{4}{|c|}{ Information provided face-to-face ( $v s$. letter or telephone) to families with } \\
\hline \multicolumn{4}{|l|}{ STEC-negative children (after initial response) } \\
\hline Letter, telephone & 197 & $26 \cdot 2$ & \\
\hline Face-to-face contact & 554 & $73 \cdot 8$ & \\
\hline \multicolumn{4}{|l|}{ Routine handling of families } \\
\hline Education about infection prevention measures: Yes & 125 & $16 \cdot 6$ & \\
\hline Education about infection prevention measures: No & 626 & $83 \cdot 4$ & \\
\hline Explanatory variable (quantitative) & Min & Median & Max \\
\hline Lag time (days) between onset and providing information & 0 & 1 & 11 \\
\hline Age (years) of STEC-positive daycare centre children & 1 & 3 & 6 \\
\hline
\end{tabular}

Table 5. Results of multilevel analysis $(n=751)$

\begin{tabular}{|c|c|c|c|c|}
\hline Descriptive variable & $\begin{array}{l}\text { Regression } \\
\text { coefficient }\end{array}$ & S.E. & $P$ value & $95 \% \mathrm{CI}$ \\
\hline Lag time (days) between onset and providing information & $1 \cdot 52$ & $0 \cdot 18$ & $<0 \cdot 01$ & $1 \cdot 16$ to $1 \cdot 88$ \\
\hline STEC type (O26 Stx1 vs. O157 Stx1 and Stx2) & $-10 \cdot 34$ & 1.67 & $<0 \cdot 01$ & -13.62 to -7.06 \\
\hline $\begin{array}{l}\text { Information provided face-to-face ( } v s \text {. letter or telephone) to } \\
\text { families with STEC-positive children (at initial response) }\end{array}$ & $-19 \cdot 15$ & $1 \cdot 67$ & $<0.01$ & $-23 \cdot 60$ to $-14 \cdot 70$ \\
\hline $\begin{array}{l}\text { Information provided face-to-face ( } v s \text {. letter or telephone) to } \\
\text { families with STEC-negative children (at initial response) }\end{array}$ & $-8 \cdot 35$ & $4 \cdot 55$ & $<0.01$ & -11.91 to $-5 \cdot 36$ \\
\hline
\end{tabular}

S.E., Standard error; CI, confidence interval.

while the rate was higher for the O157 Stx1- and Stx2-producing STEC strains than the O26 Stx1-producing strain. The rate tended to decrease when the interval (days) until provision of information was shorter, and when information was provided to families with STEC-negative DCC children faceto-face rather than by letter or telephone at the initial response.

\section{DISCUSSION}

The median rate of SecHT in our study (4.4\%) was in accordance with those reported in other studies $(3 \cdot 3-$ $15 \%)[5,11,12]$, although there was a relatively wide variation in outbreaks in our study (0-34.4\%). The chance of SecHT was higher in children than in adults, and was particularly high $(23 \%)$ in children aged 6-9 
years (Table 2). When the infected child was aged between 4 and 6 years, the SecHT rate tended to increase with the age of the child (Table 3), indicating that preschool-aged children, especially those aged 6 years, have a high risk of being the source of the infection for SecHT. Although the SecHT rates of family members might have a large difference according to age even in the same age groups, we found no significant difference in the SecHT rate in ages in three age groups: 0-5, 6-9 and 10-19 years (data not shown).

Because the children analysed, especially those aged 5 and 6 years, had a relatively high percentage of asymptomatic carriers, their guardians are likely to be less aware of transmission risk, even though only a small number of STEC organisms cause gastroenteritis. However, if children have symptoms such as diarrhoea and vomiting, the transmission risk might be relatively low because of the guardians' spontaneous awareness of infection prevention. Moreover, because children in this age group may not be completely independent with respect to daily habits, such as toiletry and hand washing, performing these activities by themselves in the absence of guardians may be related to a higher risk of infection. Several previous studies reported that a young age in index cases and siblings was associated with increased transmission risk in families [5, 11-14]. This situation might be unique in Japan and vary by country. In Japanese homes, most parents help their children with hand-washing up to the age of 4 or 5 years, this increasing trend of SecHT within the 4-6 years age group might reflect the effect of the assistance of their parents.

The highest SecHT rate in adult family members was noted for mothers. This finding may be explained by the fact that it is often mothers who take care of children at home. Therefore, education regarding the prevention of infection should be provided to families with consideration of the family structure and the level of contact with children for each family member.

Multilevel analysis showed that when a potential STEC outbreak is detected, more effective prevention of SecHT can be attained by providing early guidance to families on coping with infection by explanatory meetings with guardians and home visits rather than by letter and/or telephone. This is presumably because face-to-face contact encourages guardians to take an active attitude towards infection prevention measures, resulting in the implementation of the measures at home.

Multiple regression analysis indicated that infectivity of the O157 Stx1- and Stx2-producing STEC strains was greater than that of the O26 Stx1-producing STEC strain. In the STEC groups, STEC O157 is generally considered to have the highest infectivity $[3,15]$. As there is little information concerning the difference in infectivity between the STEC O serogroups, further studies are needed to clarify this point [16-18]. Although the results of the simple analysis of SecHT described above and the result of single regression analysis conducted as the preliminary analysis showed no significant difference between the STEC types (data not shown), the multilevel analysis indicated a significant difference between them. These results indicate there were several factors affecting SecHT rate that either equalled or surpassed the STEC type, although the STEC type had relatively strong association with SecHT rate. Therefore, providing information to families with STEC-positive DCC children in an early and effective manner might reduce the risk of SecHT regardless of STEC type. Because trace levels of all STEC strains can cause infection regardless of the $\mathrm{O}$ serogroup and Stx type, it may be important to improve surveillance and provide education about infection prevention measures outside of outbreak situations.

The results of the multilevel analysis indicated that SecHT might be reduced if the interval (days) between diagnosis at a medical institution and provision of information to families was decreased. To minimize the delay in providing information, the time required for local health centres to provide information to families should be shortened. Cooperation between local health centres and DCCs is essential, and educational activities, such as lectures for employees, should be provided so that preventive measures can be smoothly implemented in cooperation with DCCs.

The SecHT rate was not affected by the incidence of symptoms in STEC-positive children, presumably because guardians naturally paid more attention to infection prevention measures when symptoms of gastroenteritis, such as diarrhoea, occurred in their children. Because STEC can be transmitted by trace levels of bacteria, and some reports have documented the spread of infection via asymptomatic carriers [5-7], preventing the spread of infection by carriers is important, especially in outbreak settings.

The present study was designed to assess the status of SecHT of STEC and the factors contributing to SecHT. To assess the status of SecHT, we investigated STEC outbreaks involving $\geqslant 10$ children at a DCC to ensure that the source of household infection was the DCC children, i.e. the pathogen was transmitted from the children to other family members. We required 
relatively large outbreaks to avoid incidental clusters of STEC infection that might confuse the analysis and to secure the number of STEC-positive DCC children to exclude those families with $\geqslant 2$ DCC children. We determined that our study design of searching for clusters of $\geqslant 10$ cases might prevent serious bias; however, this might limit the representative study population.

This study was conducted as a retrospective cohort study investigating all outbreaks that met the criteria within a 1-year period. Although information about symptoms in family members was collected by trained local health centre staff shortly after each outbreak, accuracy levels may differ between outbreaks depending on the research skills of the staff members, and because of recall bias on the part of the interviewees.

In conclusion, our study showed that when STEC was brought into the household by DCC children, the SecHT rate was higher in brothers, sisters, and mothers than in fathers, grandfathers, and grandmothers. Therefore, differences in SecHT rate in family members should be taken into consideration when guidance is given to families on preventing infection. Because the SecHT rate was highest in children aged 6-9 years and when DCC children were aged 6 years, much more importance should be attached to providing education about hygiene practices, such as hand hygiene, to early elementary school children as well as to children in DCCs. Additionally, if a potential outbreak is detected, an early response and guidance about infection prevention measures by face-to-face contact, rather than by letter or telephone only, is useful for preventing the spread of infection. Hygiene education including hand hygiene should be provided to each family irrespective of the presence or absence of a symptomatic DCC child.

\section{ACKNOWLEDGEMENTS}

We thank all municipal health officers who assisted with this investigation in the cities of Akita, Iwaki, Kurobe, Takayama, Shizuoka, Numazu, Kyoto, Sumoto, Yonago, Tokushima, Onojo, Tosu, Isahaya, Tamana, and Miyazaki, and at the Gunma Prefectural Institute of Public Health and Environmental Sciences.

\section{DECLARATION OF INTEREST}

None.

\section{REFERENCES}

1. The National Institute of Infectious Diseases. Enterohemorrhagic Escherichia coli infection as of April 2015. Infectious Agents Surveillance Report 2015; 36: 73-74.

2. The National Institute of Infectious Diseases. Enterohemorrhagic Escherichia coli infection in Japan as of April 2007. Infectious Agents Surveillance Report 2007; 28 131-132.

3. American Academy of Pediatrics. Escherichia coli diarrhea. In: Pickering LK, et al., eds. Red Book, 29th edn. Elk Grove Village: AAP, 2012, pp. 324-330.

4. Official Report of the American Public Health Association. Diarrhea caused by Escherichia coli. In: Heymann DL, eds. Control of Communicable Diseases Manual. 18th edn. Washington DC: American Public Health Association, 2004, pp. 160-171.

5. Parry SM, Salmon RL. Sporadic STEC O157 infection: secondary household transmission in Wales. Emerging Infectious Diseases 1998; 4: 657-661.

6. Ludwig K, et al. Shiga toxin-producing Escherichia coli infection and antibodies against Stx2 and Stx1 in household contacts of children with enteropathic hemolyticuremic syndrome. Journal of Clinical Microbiology 2002; 40: 1773-1782.

7. Mannix M, et al. Large outbreak of E. coli O157 in 2005, Ireland. Eurosurveillance 2007; 12.

8. Belongia EA, et al. Transmission of Escherichia coli O157:H7 infection in Minnesota child day-care facilities. Journal of the American Medical Association 1993; 269: 883-888.

9. Seto EY, Soller JA, Colford JM Jr.. Strategies to reduce person-to-person transmission during widespread Escherichia coli O157:H7 outbreak. Emerging Infectious Diseases Journal 2007; 13: 860-866.

10. Gallagher L, et al. Outbreak of Escherichia coli O157: H7 in a child care center in Cook County, Illinois, with prolonged shedding and household transmission. American Journal of Infection Control 2013; 41: 936938.

11. Hauri A, et al. Secondary transmissions during the outbreak of Shiga toxin-producing Escherichia coli O104 in Hesse, Germany, 2011. Eurosurveillance 2011; 16.

12. Werber D, et al. Preventing household transmission of Shiga toxin-producing Escherichia coli O157 infection: promptly separating siblings might be the key. Clinical Infectious Diseases 2008; 46: 1189-1196.

13. Locking ME, et al. Escherichia coli $\mathrm{O} 157$ infection and secondary spread, Scotland, 1999-2008. Emerging Infectious Diseases 2011; 17: 524-527.

14. Snedeker KG, et al. Primary and secondary cases in Escherichia coli $\mathrm{O} 157$ outbreaks: a statistical analysis. BMC Infectious Diseases 2009; 9: 144.

15. Centers for Disease Control and Prevention. Laboratoryconfirmed non-O157 Shiga toxin-producing Escherichia coli-Connecticut, 2000-2005. Morbidity and Mortality Weekly Report 2007; 56: 29-31.

16. Wahl E, et al. Investigation of an Escherichia coli $\mathrm{O} 145$ outbreak in a child day-care centre - extensive sampling 
and characterization of eae- and stx1-positive E. coli yields epidemiological and socioeconomic insight. BMC Infectious Diseases 2011; 11: 238-249.

17. Brown JA, et al. Outbreak of shiga toxin-producing Escherichia coli serotype O26: H11 infection at a child care center in Colorado. Pediatric Infectious Disease Journal 2012; 31: 379-383.

18. Jenkins C, et al. Escherichia coli serogroup O26 - a new look at an old adversary. Journal of Applied Microbiology 2008; 104: 14-25. 